\section{VIOLÊNCIA EM TRABALHADORES FEIRANTES: RELATOS DE CASOS}

\section{VIOLENCE IN MARKET WORKERS: CASE REPORTS}

Andréia de Souza Santos ${ }^{1}$ / Deíze Carvalho Pereira ${ }^{2} /$ Maiane Silva Pereira ${ }^{1, *} /$ Marcela Andrade Rios ${ }^{1}$ / Vaneça da Silva Moreira Magalhães ${ }^{3}$

\section{INTRODUÇÃO}

Ao decorrer dos anos o mercado de trabalho tem sofrido diversas mudanças, dando destaque ao crescimento do setor informal. Dentre os diferentes ambientes da informalidade destaca-se o espaço da feira, que se apresenta como uma estratégia de manutenção de vida para àqueles que não conseguem um trabalho com garantia de condições trabalhistas favoráveis.

Os trabalhadores feirantes, geralmente, desenvolvem suas atividades laborais em condições precárias, submetemse a longas jornadas de trabalho, não dispõe de espaço apropriado para a realização das refeições e descanso, e nem desfrutam de folgas em dia de feira (CARVALHO et al., 2016).

Além dos riscos ambientais aos quais os feirantes estão expostos, foi notado em estudo realizado na feira da Sé localizada na cidade de Fortaleza, situações de conflitos entre os feirantes, no que se refere à disposição e localização das bancas, bem como a disputa por clientes (CARVALHO et al., 2016). Nesse sentido, percebe-se uma série de situações que culminam em riscos para a saúde do trabalhador feirante. Além das condições de trabalho inadequadas, o trabalhador expõe-se a riscos de violência podendo ocasionar prejuízo para a sua saúde por câncer de colo de útero e 3.879 óbitos por câncer de ovário (INCA, 2019).

\section{RESUMO}

Objetivo: Relatar casos de violência sofridos por trabalhadores feirantes de um Mercado Municipal no interior da Bahia, Brasil Materiais e Métodos: Trata-se de uma pesquisa de campo, exploratória, de abordagem qualitativa, do tipo estudo de casos, que buscou observar a ocorrências de violências em trabalhadores feirantes de um mercado municipal de uma cidade do interior baiano. Resultados: Com a construção do referido estudo notou-se que os trabalhadores feirantes vítimas de violência, são em sua maioria mulheres, a faixa etária entre 18 a 75 anos, com poucos anos de estudo, se autodeclaram pardos, solteiros e a maior parte trabalha no ramo de restaurantes. O tempo de trabalho na feira varia de meses a 30 anos, apresentando altas jornadas de trabalho, todavia a maioria relatou estar satisfeita com o trabalho. Sobre as violências, a do tipo psicológica foi a mais prevalente. Conclusão: Ressalta-se que é de suma importância que sejam tomadas medidas de combate à violência no ambiente de trabalho por parte do poder público, garantido assim, melhores condições de trabalho aos feirantes.

Palavras-chave: Saúde do Trabalhador. Setor Informal; Violência.

\section{ABSTRACT}

Objective: To report cases of violence suffered by street market workers in a Municipal Market in the interior of Bahia, Brazil. Materials and Methods: This is a field research, exploratory, qualitative approach, case study type, which sought to observe the occurrence of violence in street market workers in a city in the interior of Bahia. Results: With the construction of the aforementioned study, it was noted that market workers who are victims of violence, are mostly women, the age range varies from 18 to 75 years, a good part has low education, self-declared as brown, single and most works in the restaurant business. The working time at the fair varies from months to 30 years, with long working hours, however the majority reported being satisfied with the work. Regarding violence, the psychological type was the most prevalent. Conclusion: It is emphasized that it is of the utmost importance that measures are taken to combat violence in the workplace by the government, thus guaranteeing better working conditions for marketers.

Keywords: Occupational Health. Informal Sector. Violence.

Submetido em: 08 de nov. 2019

Aceito em: 14 de fev. 2020

\footnotetext{
${ }^{1}$ Universidade do Estado da Bahia - UNEB, Guanambi, Bahia - Brasil.

${ }^{2}$ Universidade Federal de São Paulo, São Paulo, São Paulo - Brasil

${ }^{3}$ Universidade de Brasília, Brasília, Distrito Federal - Brasil.

*E-mail para correspondência: joiceamorim.enfermagem@hotmail.com
} 
Assim, conceitua-se violência como um evento representado por ações ou omissões realizadas por indivíduos, grupos, classes, governos ou nações, que provoca danos físicos, emocionais, morais e/ou espirituais a si próprio ou a outros. Manifesta-se de diversas formas, podendo ser agressão física, violência sexual, psicológica, institucional e estrutural, entre outras (BRASIL, 2017).

Dessa forma, evidencia-se que o trabalhador feirante vivencia situações de vulnerabilidade em virtude da sua inserção precária no mercado de trabalho, sobretudo, à exposição a riscos de violência de qualquer natureza. Nessa perspectiva, este estudo tem por objetivo relatar casos de violência sofridos por trabalhadores feirantes de um Mercado Municipal no interior da Bahia, Brasil.

\section{MÉTODOS}

Trata-se de uma pesquisa de campo, exploratória, de abordagem qualitativa, do tipo estudo de casos, que buscou observar a ocorrências de violências em trabalhadores feirantes de um mercado municipal de uma cidade do interior baiano.

Participaram desde estudo 10 trabalhadores feirantes que haviam sofrido algum tipo de violência no ambiente de trabalho ou no caminho de casa para o trabalho ou do trabalho para casa, entre os meses de fevereiro de 2018 a janeiro de 2019 .

Para construção deste estudo considerou-se violência de acordo a definição dada pela Organização Mundial de Saúde - OMS, como o uso de força física ou poder, em ameaça ou na prática, contra si próprio, outra pessoa ou contra um grupo ou comunidade que leve ou possa levar ao sofrimento, morte, dano psicológico, desenvolvi- mento prejudicado ou privação (BRASIL, 1996).

As informações foram coletas entre os meses de fevereiro de 2018 a janeiro de 2019 a partir de uma ficha de coleta produzida pelos pesquisadores, contendo informações a respeito da ocorrência de acidentes de violências no trabalho. Além disso, utilizouse como subsidio as informações contidas no diário de campo que possuía impressões dos pesquisadores a respeito das situações vivencias durante a coleta.

Para a análise dos dados foram estabelecidas previamente quatro categorias a serem apresentadas e discutidas, referentes aos aspectos sociodemográficos, do trabalho na feira e do processo saúde-doença-trabalho e a descrição da violência.

O estudo foi submetido, apreciado e aprovado pelo Comitê de Ética em Pesquisa da UNEB, sob CAAE número 77090717.8.0000.0057, sendo respeitados todos os preceitos éticos das pesquisas com seres humanos citados na Resolução 466 do Conselho Nacional de Saúde.

\section{RESULTADOS E DISCUSSÃO}

Foram acompanhados 426 feirantes, estes foram questionados se sofreram algum tipo de violência no seu processo de trabalho na feira. Destes, um total de 10 trabalhadores relataram ter sofrido algum tipo de violência em seu processo de trabalho.

Dos dez indivíduos vítimas de violência, a maioria é representada por mulheres (sete). Dentre as mulheres, uma possuía 37 anos, três com idades de 40, 41 e 46 anos, uma com 50 e duas com 62 e 65 anos. Dos homens, um com 18 anos e dois com idade de 52 e 75 anos. Nota-se que no ambiente da feira trabalham pessoas de todas as idades, desde jovens a idosos, sendo assim, este espaço precisa estar devidamente preparado para oferecer devidas condições de trabalho para os diferentes públicos. Verificou-se um protagonismo feminino, sendo a maior parte dos trabalhadores do sexo feminino, bem como, as maiores vítimas de violências no processo de trabalho.

Dois dos entrevistados são divorciados/separados, cinco são solteiros, dois são casados e um vive em união estável. Todos os entrevistados convivem com mais alguém em casa, variando entre 2 a 6 pessoas. Sete dos entrevistados residem em zona urbana e um mora na zona rural. Fatores como situação conjugal e residir com outras pessoas podem ser precipitantes para que os trabalhadores desenvolvam altas jornadas de trabalho, buscando não somente o seu sustendo, mas também de outras pessoas.

Em relação à escolaridade, uma relata nunca ter frequentado escola, não sabendo ler, nem escrever; quatro pessoas cursaram até o fundamental incompleto, duas dizem ter ensino médio incompleto e três entrevistados referem ter ensino médio completo. Seis pessoas se autodeclaram pardos (a), três pretos (a), e uma considera-se branca. A escolaridade é um fator que podem interferir diretamente no conhecimento do trabalhador sobre hábitos de vida saudáveis, pois quanto menor o grau de instrução, menor seus conhecimento sobre saúde.

Dos entrevistados, uma desenvolve seu trabalho em açougue, com atividades como cortes e atendendo clientes, duas trabalham nas bancas vendendo frutas, legumes e verduras, seis pessoas trabalham nos restaurantes cozinhando, cortando carnes, legumes, verduras, atendendo clientes e também fazem a limpeza do local. 
A respeito disso, destaca-se que o espaço da feira livre é caracterizado pela presença de jornadas de trabalho exageradas, os trabalhadores são expostos diariamente a condições laborais inadequadas, existência de horários incorretos para realização da refeição, dentre outros fatores (MAGALHÃES et al., 2016). Tais questões podem interferir diretamente nas condições de saúde dos trabalhadores, levando ao aparecimento de doenças, ocorrência de acidentes e violências.

O tempo de trabalho na feira varia de alguns meses a 30 anos. Quando questionados a respeito da idade da primeira profissão e do primeiro emprego, fator que chama bastante à atenção, visto que maioria começou a trabalhar ainda criança ou adolescentes, quatro dos entrevistados alegam que possuíam de 6 a 9 anos quando iniciaram o primeiro emprego, três de 10 a 16 e três de 18 a 20 anos, realizando as seguintes atividades: babá, na feira, entregador de mercadorias e zona rural.

Corroborando com achados acima, estudo realizado com idosos açougueiros destaca que os feirantes dedicam-se muitos anos ao trabalho no ambiente da feira, isso ocorre como forma de completar a renda familiar ou até mesmo como forma de autoafirmação social, todavia, estes apresentam corriqueiramente doenças crônicas, dores em coluna vertebral e tem sua saúde prejudicada ainda mais após a ocorrência de acidentes e violências no trabalho (RIOS; VILELA; NERY, 2017).

Neste estudo, evidenciou-se que os trabalhadores começaram a trabalhar desde crianças, em atividades que necessitavam de grande demanda física, em sua maioria, estas quando desenvolvidas por muitos anos sem as devidas precauções podem levar ao adoecimento do trabalhador.

Quando questionados sobre a carga horária diária de trabalho, três responderam que trabalham 5 horas, dois disseram 6 e 7 horas, dois 8 horas, um 10 horas e dois 12 horas. Acordam entre 03:00 e 07:00 da manhã no dia que vão trabalhar. Em relação à jornada de trabalho semanal, três pessoas declaram trabalhar de 10 a 20 horas semanais, três de 30 a 35 horas, duas feirantes trabalham de 40 a 45 horas e duas alegam trabalhar até 84 horas por semana.

Assim, nota-se que a existência de extensas jornadas de trabalho são assumidas, devido questões financeiras, ou seja, não se trata de uma livre escolha do trabalhador, mas é necessária como estratégia para complemento da renda (LACERDA, 2014).

No que diz respeito aos riscos oferecidos pelo trabalho, a maioria dos entrevistados refere não perceber fatores de risco para a saúde no desenvolver das suas atividades laborais, sendo que, apenas três disseram que o trabalho apresenta risco. Cortes, quedas, queimaduras e agressões foram os mais referidos. Apesar dos riscos descritos, a maioria relata estar satisfeito com o seu trabalho atual.

Nesse sentido, percebe-se que mesmo com a ocorrência de acidentes e violências no trabalho ou o risco para tal, os trabalhadores sentem-se satisfeitos com suas atividades laborais diárias e compreendem que a causa para o aparecimento de tais agravos se dá devido atos inseguros cometidos pelos trabalhadores (RIOS; VILELA; NERY, 2017).

Visando obter mais informações acerca da vivência de cada um e quanto à presença de fatores precipitantes para ocorrência de acidentes e violência, os trabalhadores foram questiona- dos sobre período de férias, sete disseram nunca tirar férias e dois informaram que sim. Ressalta-se, que a maioria dos trabalhadores entra de férias durante os feriados. Percebe-se, que a maioria dos trabalhadores não usufrui o direito de férias, trabalhando sem folgas, o que pode ocasionar sobrecarga de trabalho, exaustão, insatisfação e estresse.

Quando questionados sobre o padrão de sono, sete responderam que dormem bem e três disseram que não, sendo as possíveis causas de insônia, as preocupações, o cansaço, dores musculoesqueléticas, hábito de acordar cedo. Embora um número pequeno de trabalhadores referisse não dormir bem, esse dado deve ser levado em consideração, tendo em vista a importância do padrão de sono regular para a saúde do indivíduo, uma vez que o estresse no ambiente de trabalho pode ocasionar distúrbios do sono, dentre outros problemas (OPAS/OMS, 2016).

Segundo estudos realizados em uma empresa metalúrgica do município de São Bernardo do Campo (SP), notou-se que, os funcionários passavam por diversos problemas além do adoecimento, eles também sofriam de assédio moral, implicando riscos psicossociais levando os mesmos a condições depressivas e ao uso de psicoterápico, pensamento suicída, dificuldade para dormir, dificuldade de realizar afazeres diários e comportamentos agressivos. (PINTOR e GARBIN, 2018).

Ao serem indagados se conseguem manter uma discussão sem se alterar, mesmo quando contrariados, quatro disseram nunca conseguir, um disse que consegue às vezes, um quase sempre e quatro responderam que sempre conseguem. A partir destes relatos, pode-se inferir que situações 
que desencadeiam estresse podem ser precipitantes para prática da violência.

Analisados os aspectos referentes à saúde dos feirantes, nove feirantes referiram ter algum tipo de doença, enquanto um não apresentou diagnóstico para nenhuma doença. Dos nove feirantes que possuíam doenças, um declarou ser portador de doença musculoesquelética, um bronquite crônica, dois alergias, dois já haviam apresentado quadro de insuficiência cardiovascular e infarto agudo do miocárdio, sendo que um deles apresentou além das doenças citadas tuberculose pulmonar e hipertensão arterial, acidente vascular cerebral e o outro sinusite crônica. Três deles não citaram as doenças que possuíam.

Sobre a presença de doenças em trabalhadores feirantes, evidencia-se que as condições de trabalho, quando inadequadas, interferem negativamente na saúde do indivíduo, contribuindo assim, para o surgimento de doenças, modificações emocionais e déficit de informação acerca de hábitos de vidas saudáveis (MAGALHÃES et al., 2016)

Segundo as violências sofridas, sete foram do tipo psicológico, sendo que três relataram que essa violência foi praticada por colegas de trabalho, duas disseram que partiu de clientes, uma disse ter sido vítima de chacotas (piadas), uma narra ter partido do proprietário da banca que ela utiliza (era uma banca emprestada). Foram descritas três violências do tipo física, sendo que uma ocorreu por parte da esposa no ambiente da feira, uma decorrente de um indivíduo pedinte, e uma por um freguês que estava embriagado.

A respeito disso, pesquisa aponta que a violência psicológica trás consigo agravos ao trabalhador, gerando consequências em seu estado de saúde e atingindo seu lado pessoal.
Logo, ressalta-se uma importante interferência do poder público, afim, de impedir esse tipo de ação no ambiente laboral (PINTOR e GARBIN, 2018).

Sabe-se que vários fatores podem influenciar que o trabalhador, em seu ambiente de trabalho, sofra uma prática de violência. A exemplo disso destaca-se a ocorrência de abuso verbal no ambiente de trabalho, que por usa vez, repercute em uma situação de reconhecimento da capacidade do trabalhador e se associa à falta de reconhecimento profissional, gerando certa repressão entre os mesmos (TSUKAMOTO et al., 2019).

Nenhum dos feirantes procurou estabelecimento de saúde e apenas uma informa ter tido tratamento de saúde com soro fisiológico por conta própria em sua residência.

Dentre os casos de violência, somente um apresentou lesão física (hematoma), sendo que o mesmo vitimou uma senhora que registrou uma das maiores cargas horárias de trabalho de acordo os casos analisados. Dos casos em estudo, oito referem ter tido dano psicológico, enquanto dois não relataram.

Sobre este achado, estudo aponta que as mulheres são mais expostas à violência, sendo essa do tipo violência psicológica, com agressão verbal, e seguida da violência física que também se fez presente (PAI et al, 2018).

Ao serem questionados se teria como evitar o incidente, sete disseram que não, sendo que um alegou ser normal a ocorrências destes devido a convivência entre as pessoas no ambiente da feira, enquanto outro diz ser algo que acontece no trabalho e cinco não justificaram sua resposta. Três entrevistados disseram que sim, que poderia ser evitado, sendo que um disse que a melhor forma para isso seria o diálogo, outro relatou que man- ter o respeito entre colegas é a melhor maneira de evitar tal agravo e um não completou sua justificativa.

Nesse sentido, a violência pode ser compreendida como fruto de interações humanas que a partir de situações vivenciadas em um lugar precário e agitado de trabalho, ou formas de insatisfação entre envolvidos, trabalhadores e usuários, com as condições em que são subordinados a viver (PAI et al., 2018).

Para tanto, os investimentos públicos são uma das medidas de segurança com fins de conter e tratar os casos de agressão. $\mathrm{O}$ vínculo empregatício influencia em uma prática de violência, e as agressões geralmente entre profissionais acabam sendo negadas diante da fraqueza e péssimas condições de trabalho e relações sociais (PAI et al., 2018).

\section{CONCLUSÃO}

Com a construção do referido estudo notou-se que os trabalhadores feirantes vítimas de violência são em sua maioria mulheres, a faixa etária varia de 18 a 75 anos entre os casos estudados, boa parte possuí baixa escolaridade, de autodeclaram pardos, a grande maioria é solteiro e a maior parte trabalha no em restaurantes.

O tempo de trabalho na feira varia de meses a 30 anos, apresentando altas jornadas de trabalho semanais, todavia a maioria relatou estar satisfeita com o trabalho atual. Sobre as violências. As mesmas acometeram em sua maioria mulheres, sendo a violência mais comum do tipo psicológica.

Percebe-se que o trabalho informal na feira expõe o trabalhador as condições insalubres, levando a ocorrências que acidentes e violências durante a prática laboral. Situações como a ata carga horária, alimentação 
inadequada, problemas financeiros entre outros, podem levar a elevação do nível de estresse do trabalhador, desencadeando a prática da violência.

Algumas dificuldades foram encontradas durante a construção deste estudo, principalmente no que diz respeito à literatura, pois a mesma apresenta-se escassa de estudos a respeito da violência no setor informal.

Ressalta-se que é de suma importância que sejam tomadas medidas de combate à violência no ambiente de trabalho por parte do poder público, garantido assim, melhores condições de trabalho aos feirantes, para que estes desenvolvam seu trabalho com o menor grau de risco possível.

\section{REFERÊNCIAS}

BRASIL. Ministério da Saúde. Secretaria de Atenção à Saúde. Departamento de Ações Programáticas e Estratégicas. Proteger e cuidar da saúde de adolescentes na atenção básica [recurso eletrônico] Brasília: Ministério da Saúde, 2017.

CARVALHO, R. G. et al. Situações de trabalho e relatos de dor entre feirantes de confecções. Rev Psicol Organ Trab, v. 16, n. 3, p. 274-284, jul-set. 2016.

LACERDA, M. et al., A

(in)visibilidade do acidente de trabalho fatal entre as causas externas: estudo qualitativo. Rev bras Saúde ocup. v. 39, n. 130, p. 127-135, 2014.

MAGALHÃES, A. H. R. et al. Necessidade de saúde das mulheres feirantes: acesso, vínculo e acolhimento como práticas de integralidade. Revista Gaúcha de Enfermagem. v. 37. p. 0026, 2016.

OPAS/OMS. Organização Pan-

Americana de Saúde/ Organização Mundial da Saúde. Estresse no ambiente de trabalho cobra preço alto de indivíduos, empregadores e sociedade. 2016. Disponível em: <https://www.paho.org/bra/index.php? opion=com_content $\&$ view $=$ article $\&$ id =5087:estresse-no-ambiente-detrabalho-cobra-preco-alto-deindividuos-empregadores-esociedade \&Itemid=839>. Acesso em: 07 Out. 2019.

PAI, D. D. et al. Violência física e psicológica perpetrada no trabalho em saúde. Texto Contexto Enferm. v. 27, n. 1, p. 242-0016, 2018.

PINTOR, E. A. S; GARBINB, A. C. Notificações de violência relacionadas ao trabalho e vigilância em saúde do trabalhador: rompendo a invisibilidade. Rev Bras Saude Ocup. v. 44, n. 20, p. 1-9, 2019. 29

RIOS, M. A; VILELA, A. B. A; NERY, A. A. O trabalho e a saúde de açougueiros idosos: relato de casos em um mercado municipal. Rev. Bras.

Geriatr. Gerontol. v. 20, n. 5, p. 644650, 2017.

TSUKAMOTO, S. A. S. et al. Violência ocupacional na equipe de enfermagem: prevalência e fatores associados. Acta Paul Enferm. v. 32, n. 4, p. 4253, 2019.

WHO. World Health Organization. Global consultation on violence and health. Violence: a public health priority. Geneva: WHO, 1996. 